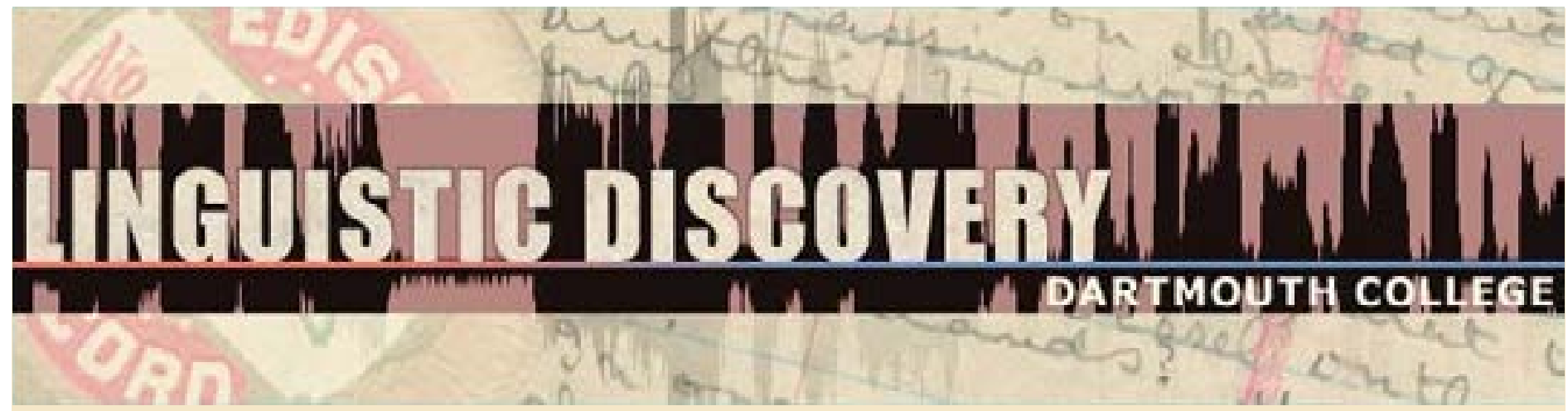

\begin{tabular}{|l|}
\hline Volume 10 \\
Issue 3 \\
2012 \\
\hline
\end{tabular}

\title{
Ditransitive Alignment and Referential Hierarchies in Araki
}

Alexandre François

LACITO-CNRS, Australian National University

doi: 10.1349/PS1.1537-0852.A.418

url: http://journals.dartmouth.edu/cgi-bin/WebObjects/ Journals.woa/1/xmlpage/1/article/418

Linguistic Discovery

Published by the Dartmouth College Library Copyright to this article is held by the authors. ISSN 1537-0852 linguistic-discovery.dartmouth.edu 


\title{
Ditransitive Alignment and Referential Hierarchies in Araki
} Alexandre François

\author{
LACITO-CNRS, Australian National University
}

Since Bossong (1985), referential hierarchies have proven useful in accounting for patterns of differential object marking (DOM) in monotransitive clauses. More recent studies (Siewierska 1998; Haspelmath 2005; Bickel 2008; papers in this volume) have also shown the relevance of such hierarchies in explaining the alignment patterns of ditransitive verbs - that is, how languages treat formally the Theme and the recipient or Goal. Araki, a highly endangered Oceanic language of Vanuatu, not only shows DOM with its transitive verbs, but is also sensitive to referential properties of arguments in its handling of ditransitive alignment. On a hierarchy defined by the features [ \pm local] (i.e. speech-act participant) and [ \pm thuman], the higher-ranking participant receives the status of object, while the other one is demoted to a peripheral role. The result is a pattern of regular alternation between indirective and secundative alignment, depending on the relative properties of the Theme and the Goal. The present article will describe these patterns, and discuss cases of variation. Ultimately, rules of ditransitive alignment in Araki can be explained functionally as a competition between non-agent participants on a scale of affectedness.

\section{Introduction}

\subsection{General background}

A number of authors - including Dryer (1986), Haspelmath (2005, 2011), Malchukov et al. (2010) - have highlighted the parallelism between two problems of syntactic typology: monotransitive alignment and ditransitive alignment ${ }^{1}$. First, monotransitive alignment is concerned by which of the two arguments of a (mono)transitive clause (A the agent, P the patient) will be formally treated like the sole argument of an intransitive clause (S). As for the study of ditransitive alignment, it is concerned with the two non-agent arguments of a threeparticipant clause, namely the theme (T) and the recipient or goal $(\mathrm{G})$; the question raised, this time, is which of these two arguments (T or G) will align with P, the sole non-agent argument of the monotransitive clause.

If the participant aligning with $\mathrm{P}$ is the Theme, we have an indirect object construction, or indirective alignment. This pattern - of the type She gave water to the guests - is typologically the most common (Haspelmath 2011). Yet in many languages, the participant that aligns with the patient is the Goal, as in She provided the guests with water: this defines secundative alignment. A third possible alignment type, called double-object construction or neutral alignment, consists for both $\mathrm{T}$ and $\mathrm{G}$ to be aligned with $\mathrm{P}$, as in English She gave them water (Malchukov et al. 2010).

Languages of the world differ greatly in their strategies for encoding three-participant verbs -

\footnotetext{
${ }^{1}$ I wish to thank the speakers of Araki who helped me document their language - in particular, the late $\dagger$ Lele Moli and his sons Uhu, Valaua and Grem. This study would not have been possible without Eva van Lier, who invited me to join the volume she was editing, and gave me the opportunity to carry out new fieldwork on Araki - with the precious support of Anna Siewierska, and of the EuroBabel project Referential hierarchies in morphosyntax. Together with two anonymous reviewers, Eva has greatly helped me improve earlier versions of this paper, and deserves all my gratitude.
} 
the focus of the present volume. Some follow one alignment type consistently, whether indirective, secundative, or neutral. Other languages show mixed systems, with more or less regular alternation between alignment types, depending on various possible criteria. Relevant factors may have to do with the lexical semantics of the verb; or, say, with the morphological realisation of arguments (e.g. pronouns versus noun phrases). But in many cases, crucial parameters include the referential properties of these arguments, i.e. those semantic features that are inherent to the referents themselves: e.g. definiteness, specificity, number, animacy, person. The present study will precisely focus on Araki, a language in which the syntax of ditransitive alignment follows complex yet regular split patterns, depending on the referential properties of its arguments.

\subsection{The case of Araki}

Araki is an Oceanic (Austronesian) language spoken on the small island of the same name, off Espiritu Santo island in Vanuatu. With only eight speakers left, Araki is a moribund language: a number of social factors in the $20^{\text {th }}$ century have resulted in Araki islanders shifting to the neighbouring language Tangoa (Vari-Bogiri 2005). Araki has been the object of a grammatical description, a dictionary and a collection of texts (François 2002, 2008). The present article builds on data collected by the author in 1997-1998 and 2011, with the last speakers of the language.

One of the particularities of Araki is the syntactic treatment it gives to different kinds of participants, both in its monotransitive and ditransitive constructions. The present paper will compare the encoding of Patients in two-participant constructions with the morphosyntactic treatment of Themes and Goals in three-participant constructions. I will highlight the contribution of two major parameters underlying these constructions: first, the nature of lexical verb classes; second, the referential properties of participants, including humanness, anaphoricity, and person.

In the discussion, I will use the terms Patient, Theme and Goal in accordance with the generalised role model proposed by Bickel and Nichols (2009) and Bickel (2010). According to this approach, a two-participant event defines an agent-like (A) and a non-agent-like or patientlike (P) participant. A three-participant event involves an A and two non-agent-like participants. For the latter, a basic distinction is assumed between a manipulated participant, the Theme (T), and a stationary participant, the Goal $(\mathrm{G})$. In principle, the label ' $\mathrm{G}$ ' encompasses locational goals as well as (human) recipients.

In a nutshell, I will first show that Araki treats the $\mathrm{P}$ of monotransitive clauses in two different ways, according to its referential properties; this is a classic case of Differential object marking (Bossong 1985). Three-participant clauses also show a formal split between two constructions, namely the secundative vs the indirective. This alternation, which is only observed with a small set of ditransitive verbs, is driven by the intrinsic properties of $\mathrm{G}$ and $\mathrm{T}$, and their relative position on a hierarchy of referential properties. Overall, the factors determining the encoding of monotransitive Patients overlap with those that condition the encoding of ditransitive Themes and Goals: in both cases, one can define a scale of saliency in which more salient referents (speech-act participants, human and/or definite specific referents) outrank less salient ones. Ultimately, building upon Næss (2007), I will propose to correlate these formal distinctions of Araki with the degree of affectedness of non-agent participants. 


\subsection{Outline}

The paper is organised as follows. I start out, in section 2, with a brief overview of some relevant major characteristics of Araki grammar. Section 3 discusses the encoding of $P$ in two-participant constructions; I'll show that differential P-marking affects verbal indexation (with most verbs) and prepositional flagging (with some verbs). Both types of argument marking are in turn dependent on the referential properties of $\mathrm{P}$, in terms of humanness, anaphoricity, and specificity.

Section 4 addresses the encoding of $\mathrm{T}$ and $\mathrm{G}$ in three-participant constructions. What we find here is a basic distinction between three common ditransitive verbs ('give', 'show', 'tell') on the one hand, and other verbs that semantically imply three participants. Whereas the latter group of verbs always show indirective alignment ( $\mathrm{T}$ aligns with $\mathrm{P})$, the former three verbs, in contrast, exhibit an alternation between indirective alignment ( $T$ aligns with $\mathrm{P}$ ) and secundative alignment ( $\mathrm{G}$ aligns with $\mathrm{P}$ ). This alternation is driven by the competition between $\mathrm{T}$ and $\mathrm{G}$ for the status of object; it depends on the relative referential properties of $\mathrm{T}$ and $\mathrm{G}$, in terms of a hierarchy that involves the dimensions of humanness and person.

Finally, Section 5 will discuss these results, and propose a functional explanation in terms of affectedness. In particular, I will address the question of why only 'give', 'show', and 'tell', but not other verbs, show this reference-sensitive alternation in their patterns of ditransitive alignment.

\section{Overview of Clause Syntax in Araki}

The grammar of Araki was first described by François (2002). I will only refer here to those points which will be relevant for the later discussion on ditransitive verbs.

\subsection{Parts of speech and subject clitics}

The main parts of speech of Araki include nouns, locatives, numerals, verbs, and adjectives. The first two of these are directly predicative: they form direct predicates, with no copula. ${ }^{2}$

$$
\begin{array}{lll}
\ddot{\text { Pira }} \text { hosu } & \langle\text { naivou-ku }\rangle_{\text {PRED }} \text {. } \\
\text { woman that } & \text { wife-my }
\end{array}
$$

'That woman is my wife.'

$$
\begin{aligned}
& \ddot{M a-k u} \quad \text { ai }\langle\text { kesi }\rangle_{\text {PRED }} \text {. } \\
& \text { POSS:DRINK-1s water here } \\
& \text { 'My (glass of) water is here.' }
\end{aligned}
$$

When they form the head of a predicate, verbs are accompanied by clitics. While tense-aspectpolarity clitics are optional, the subject-and-mood proclitic is obligatory. This is a portmanteau

\footnotetext{
${ }^{2}$ The orthography used in this paper follows conventions recently adopted by the community, which partly differ from the spelling used in François (2002). Most symbols stand for their IPA value, except $n g[\mathrm{r}] ; j[\mathrm{t}]] ; r[\mathrm{r}] ; \bar{r}[\mathrm{r}]$; consonants with umlaut represent apicolabials: $\ddot{p}[\mathrm{t}] ; \ddot{m}[\mathrm{n}] ; \ddot{V}[ð]$. Example sentences are glossed according to the Leipzig rules; more specific abbreviations include: CSTR: construct suffix (\$3.2.1); INDEP: independent pronoun; IPFV: imperfective; Irr: Irrealis; FARMING: possessive classifier for items related to farming; POSS:DRINK: possessive classifier for drinks; PROH: prohibitive; R: Realis.
} 
morpheme which indexes the mood value of the clause (Realis vs Irrealis) as well as the subject of the predicate:

$$
\begin{aligned}
& \mathrm{Nam}=\overline{\mathrm{r}} \mathrm{hho}=\overline{\mathrm{r}} \mathrm{k} \text { kesi. } \\
& 1 \mathrm{~s}: \mathrm{R} \text { stay IPFV here } \\
& \text { 'I live here.' }
\end{aligned}
$$

Table 1 lists the subject proclitics for Realis and Irrealis (François 2002:44).

\begin{tabular}{|c|c|c|c|c|}
\cline { 2 - 5 } \multicolumn{1}{c|}{} & \multicolumn{2}{c|}{ Realis } & \multicolumn{2}{c|}{ Irrealis } \\
\cline { 2 - 5 } \multicolumn{1}{c|}{} & SING & PLUR & SING & PLUR \\
\hline 1INC & & jam $=$ & & jo $=$ \\
1EXC & nam $=$ & kam $=$ & na $=$ & kamä $=$ \\
$\mathbf{2}$ & om $=$ & ham $=$ & $\mathrm{o}=$ & ha $=$ \\
$\mathbf{3}$ & mo $=$ & mo $=$ & jo $=$ & ha $=$ \\
\hline \multicolumn{2}{c|}{ Table 1: Proclitics indexing subject and mood } \\
\hline
\end{tabular}

These subject-and-mood proclitics do not take exclusively verbs under their scope: they also combine with a number of predicative parts of speech, including numerals (e.g. rua 'two' in (63) below); nouns in some contexts; and adjectives. However, each of these categories have morphosyntactic properties that distinguish them from verbs (François 2002:33 sqq.). Table 2 summarises some of these properties, including the possibility to form a predicate, or modify a

\begin{tabular}{|c|c|c|c|c|c|}
\hline & $V E R B$ & NUMERAL & ADJECTIVE & NOUN & LOCATIVE \\
\hline $\begin{array}{l}\text { predicate } \\
\text { with Sbj clitic }\end{array}$ & + & + & + & + & - \\
\hline $\begin{array}{l}\text { noun modifier } \\
\text { with Sbj clitic }\end{array}$ & - & + & - & - & - \\
\hline $\begin{array}{l}\text { predicate } \\
\quad \text { without Sbj clitic }\end{array}$ & - & - & - & + & + \\
\hline $\begin{array}{l}\text { noun modifier } \\
\text { without Sbj clitic }\end{array}$ & - & - & + & + & + \\
\hline
\end{tabular}
noun, with versus without a subject-mood proclitic. The present study will focus on verbal clauses.

Table 2: Properties of main parts of speech in Araki

\subsection{Syntax of verbal clauses}

Araki shows nominative-accusative alignment: the subject $\mathrm{S}$ of its intransitive clauses aligns with the A of transitive clauses. Compare (4) with (3) above.

$$
\begin{aligned}
& \mathrm{Nam}=\text { je var̄i-a. } \\
& 1 \mathrm{~s}: \mathrm{R} \text { NEG take-3s:OBJ } \\
& \text { 'I didn't take it.' }
\end{aligned}
$$

The order of clausal elements in Araki is strictly SVO (SV, AVO). Non-core arguments and 
adjuncts follow the object.

$$
\begin{aligned}
& \text { Nra mo }=\text { heli-a koko lo jarauta. } \\
& \text { 3pl 3:R dig-3s:OBJ hole LOC shore } \\
& \text { 'They dug a hole on the shore.' }
\end{aligned}
$$

Section 3 below will present the morphosyntax of transitive clauses in more detail.

Araki has two patterns of verb serialisation. One, akin to verb compounding, is nuclear-layer serialisation (cf. Foley and Olson 1985). A sequence of two verbs behaves morphologically like a single verb, insofar as they index their subject and object only once:

$$
\begin{aligned}
& \mathrm{Na}=\text { pa }=\langle\text { pisu jurungi }\rangle-\mathrm{a} \text { aka-ja. } \\
& \text { 1s:Irr FUT prick pierce-3s:OBJ canoe-1inc:pl } \\
& \text { 'I'm going to make a hole in our boat!' }
\end{aligned}
$$

The other pattern, named "clause chaining" by François (2002:189-199), corresponds to Foley and Olson's core-layer serialisation. What are serialised are not just verb stems, but entire verb phrases, each of which encodes its own arguments:

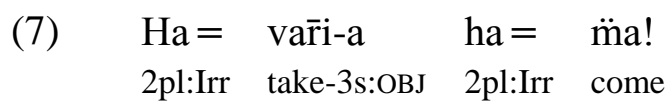

'Bring it here!'

This form of serialisation, highly frequent in discourse, will be mentioned again briefly in $\S 3.2$ and $\S 4.1$.

\section{The Encoding Of Patients in Two-Participant Constructions}

\subsection{Patients encoded as core arguments}

With most two-participant verbs, the Patient is treated as a core argument. This particular combination (non-agent-like participant in a transitive clause + core argument) defines the syntactic function of (direct) object in this language. This contrasts with non-core arguments, which will be described in $\$ 3.2$.

\section{OBJECT OTHER THAN THIRD PERSON}

When the object is other than $3^{\text {rd }}$ person, it normally takes the form of a weak object pronoun, which is realised as a suffix on the verb. This is the case with $1 \mathrm{sg}, 2 \mathrm{sg}$ and 1incl.pl objects:

$$
\begin{array}{lll}
\langle\text { Naivou-ku }\rangle_{\mathrm{A}} & \mathrm{mo}= & \text { poi-á. } \\
\text { wife-my } & 3: \mathrm{R}= & \text { like-1s.oBJ } \\
\text { 'My wife likes me.' } &
\end{array}
$$




$$
\begin{array}{lll}
\langle\text { Naivou-ku }\rangle_{A} & \mathrm{mo}= & \text { poi-ko. } \\
\text { wife-my } & 3: \mathrm{R}= & \text { like-2s.OBJ }
\end{array}
$$

'My wife likes you.'

$$
\begin{array}{lll}
\langle\text { Naivou-ku }\rangle_{\mathrm{A}} & \mathrm{mo}= & \text { poi-ja. } \\
\text { wife-my } & 3: \mathrm{R}= & \text { like-1in:pl.oBJ }
\end{array}
$$

'My wife likes us.'

Table 3 lists all the pronominal suffixes of Araki, both verbal and nominal - as both will be

\begin{tabular}{|c|c|c|c|c|}
\hline & \multicolumn{2}{|c|}{$\begin{array}{c}\text { VERBAL SUFFIXES } \\
\text { (object of verbs }+ \\
\text { object of verb-like prepositions) }\end{array}$} & \multicolumn{2}{|c|}{$\begin{array}{c}\text { NOMINAL SUFFIXES } \\
\text { (possessor of nouns }+ \\
\text { object of noun-like prepositions) }\end{array}$} \\
\hline & SING & PLUR & SING & PLUR \\
\hline 1INC & & $-j a$ & & $-j a$ \\
\hline 1EXC & -á & - & $-k u$ & -mä \\
\hline 2 & -ko & - & $-m$ & -mïim \\
\hline 3 & $-a$ & -ra & -na & -ra \\
\hline
\end{tabular}
relevant to our forthcoming discussions, especially §3.2. Note that the paradigm of verbal suffixes is defective: for two persons in the plural (1ex:pl, 2pl), the object takes the form of a free pronoun in a full NP slot, as in (17) below.

Araki has regular penultimate stress; when stress is irregular, it is marked in the orthography with a diacritic. This is relevant for the contrast between the object suffixes for $3 \mathrm{sg}$ and $1 \mathrm{sg}$, which are respectively /-a/ (with regular stress on previous syllable) vs /-ál (with unpredictable final stress): e.g. rueni-a [rue'ni.a] 'help him/her' vs rueni-á [rueni'a] 'help me'.

\section{THIRD PERSON OBJECTS}

When the object is $3^{\text {rd }}$ person, its encoding depends on its referential properties in terms of anaphoricity and humanness.

When a $3^{\text {rd }}$ person object is topical and activated, it is expressed by a weak object pronoun, whether it is human or not. Both $3 \mathrm{sg} /-a /$ and $3 \mathrm{pl} /-\mathrm{ra} /$ are underspecified with respect to gender or animacy:

$$
\begin{aligned}
& \langle\text { Naivou-ku }\rangle_{\mathrm{A}} \quad \mathrm{mo}=\text { poi-a. } \\
& \text { wife-my } \quad 3: \mathrm{R}=\quad \text { like-3s.oBJ } \\
& \text { 'My wife likes him her it.' } \\
& \langle\text { Naivou-ku }\rangle_{\mathrm{A}} \quad \mathrm{mo}=\text { poi-ra. } \\
& \text { wife-my } \quad 3: R=\text { like-3p:OBJ }
\end{aligned}
$$

When the object is not topical or activated, it takes the form of a full noun phrase. In this case, a 
formal split is drawn between human and non-human referents. A [-human] NP object is indexed on the verb by an agreement suffix which inflects for number - see (13)-(14), and also (5)-(6) above:

$$
\begin{array}{llll}
\langle\text { Naivou-ku }\rangle_{\mathrm{A}} \quad \mathrm{mo}= & \text { poi-a } & \text { hija-m. } \\
\text { wife-my } & 3: \mathrm{R} & \text { like-3s:OBJ } & \text { name-your } \\
\text { 'My wife likes your name.' } &
\end{array}
$$

$$
\begin{array}{llll}
\langle\text { Naivou-ku }\rangle_{\mathrm{A}} & \mathrm{mo}= & \text { poi-ra } & \ddot{\text { pep̈e. }} \\
\text { wife-my } & \text { 3:R } & \text { like-3p:OBJ } & \text { butterfly }
\end{array}
$$

'My wife likes butterflies.'

These agreement suffixes are the same as the $3^{\text {rd }}$ person weak object pronouns of (11)-(12), and will be glossed here in the same way; however, agreement suffixes only occur with [-human] NPs. By contrast, [+human] NP objects do not trigger agreement on the verb:

$$
\begin{array}{llll}
\langle\text { Naivou-ku }\rangle_{\mathrm{A}} \quad \mathrm{mo}= & \text { poi- } \varnothing & \text { naivou-m. } \\
\text { wife-my } & 3: \mathrm{R} & \text { like- } \varnothing & \text { wife-your } \\
\text { 'My wife likes your wife.' } &
\end{array}
$$

$$
\begin{array}{lccc}
\langle\text { Naivou-ku }\rangle_{\mathrm{A}} \quad \mathrm{mo}= & \text { poi- } \varnothing & \text { Sera. } \\
\text { wife-my } & 3: \mathrm{R} & \text { like- } \varnothing & \text { Sarah } \\
\text { 'My wife likes Sarah.' } & &
\end{array}
$$

$$
\begin{array}{llll}
\langle\text { Naivou-ku }\rangle_{\mathrm{A}} \quad \mathrm{mo}= & \text { poi- } \varnothing & \text { kam̈im. } \\
\text { wife-my } & 3: \mathrm{R} & \text { like- } \varnothing & \text { 2pl:INDEP } \\
\text { 'My wife likes you guys.' } &
\end{array}
$$

This encoding of objects depending on the feature [ \pm human] will be relevant later, in $\$ 4.4$. Even though this is a classic case of differential object marking (Lazard 1984, Bossong 1985), the fact that [+human] vs [-human] Ps are associated respectively with zero vs non-zero markers runs counter to cross-linguistic expectations. The typologically more common pattern is for more salient referents to be overtly indexed (Siewierska 2004). However, Siewierska (2004: 150) shows that this generalisation is much stronger for A than for $\mathrm{P}$ arguments, and she in fact identifies several languages that exhibit agreement only with less salient P-arguments. This finding is in line with diachronic studies, showing that in some languages the development of Pagreement starts off with more salient P-types, but in others with less salient Ps (Van Gelderen 2011). ${ }^{3}$

\subsection{Patients encoded as non-core arguments}

Non-core arguments in Araki, regardless of their semantic role, are flagged by means of prepositions. In what follows, I shall focus on three prepositions, namely lo 'locative', $(i) n(i)$

\footnotetext{
${ }^{3}$ I thank Eva van Lier for pointing out these references to me.
} 
'oblique', and (i)sa 'dative', as they will be relevant to the discussion on three-participant constructions.

\section{A NOTE ON THE MORPHOLOGY OF ARAKI PREPOSITIONS}

The two prepositions $(i) n(i)$ and $(i) s a$ show free variation with and without a vowel $i$, e.g. ini-a= $n i-a$ 'of him it'; $i s a-k u=s a-k u$ 'to me'. These alternations are optional, and will be irrelevant to this study.

Some prepositions, including lo 'locative', always occur as a fixed form followed by an NP, and never inflect. By contrast, other prepositions may take pronominal dependents as their object. They inflect for person and number in two distinct ways (François 2002:158):

- "Verb-like prepositions", including $(\boldsymbol{i}) \boldsymbol{n}(\boldsymbol{i})$ 'oblique', take the same object suffixes as verbs (Table 3) - e.g. (i)ni-á <OBL-1s> 'of me', (i)ni-ko <OBL-2s> 'of you', (i)ni-a $<$ OBL-3s> 'of him', etc.

- "Noun-like prepositions", including (i)sa 'dative', take the same possessive suffixes (Table 3) as inalienably possessed nouns - e.g. (i)sa-ku <DAT-1s> 'to me', (i)sa-m $<$ DAT-2s> 'to you', (i)sa-na <DAT-3s> 'to him', etc.

The two types of prepositions also behave differently when they combine with a full Noun Phrase. A verb-like preposition appears in its bare form, followed directly by its dependent. The oblique preposition $(i) n(i)$ is thus sometimes reduced to a single consonant - as in (21) $n$ naru-m.

A noun-like preposition, by contrast, will take a "construct suffix (CSTR)" $-n$. When suffixed to a possessed noun, the $-n$ is found on the head of a possessive phrase to mark it as possessed by the following NP: ${ }^{4}$

$$
\begin{array}{ll}
\text { naru- } n & \text { moli } \\
\text { son-CSTR } & \text { chief }
\end{array}
$$

'the son of the chief'

In the same way, this head-marking construct suffix appears on noun-like prepositions when their object is a Noun Phrase:

$$
\begin{aligned}
& \text { Sa- } n \quad \text { moli } \\
& \text { DATIVE-CSTR chief } \\
& \text { 'to the chief' }
\end{aligned}
$$

In sum, the dative preposition has the form (i)sa when followed by a pronominal suffix (isa-ku, $i s a-m$, isa-na...), and (i)sa- $n$ when followed by an NP.

\section{OBLIQUE AND LOCATIVE MARKED PATIENTS}

With some two-participant verbs, the $\mathrm{P}$ argument is encoded in a preposition phrase rather than

\footnotetext{
${ }^{4}$ Head-marking in possessive constructions is common in Oceanic (Lichtenberk 1984; Ross 2004:514), and also found in other language families (Kihm 2000).
} 
an object. These cases correspond to what Dixon and Aikhenvald (2000) name "extended intransitives", and will be identified here as "non-core Patient". Incidentally, the prepositional marking of $\mathrm{P}$ suspends the possibility of triggering verbal agreement.

The choice of the preposition depends partly on the lexical verb: some require a dative argument (see below), while others require an oblique $(i) n(i)$ or a locative lo preposition. For the latter category of verbs, the choice of the right preposition depends, this time, on the referential properties of $\mathrm{P}$.

The preposition $(i) n(i)$, glossed as 'oblique', introduces $\mathrm{P}$ if it is a pronoun (human or not), a proper noun, or a common noun that is [+human] [+specific]:

$\begin{array}{lllllll}\text { Mara } & \text { rungana } & \text { hosu } & \text { mo }= & \text { les les } & \text { te } & \text { ni-ra. } \\ \text { since } & \text { time } & \text { that } & 3: R & \text { look RECIP } & \text { bad } & \text { OBL-3p }\end{array}$

'Since that time, they have always hated each other.' [lit. looked bad at each other]

$$
\begin{array}{lll}
\text { Nam }= & \text { lolokoru } \quad \mathbf{n} & \text { nar̄u-m. } \\
\text { 1s:R be.angry OBL } & \text { son-2s } \\
\text { 'I'm angry at your son.' }
\end{array}
$$

The preposition $l o$ 'locative' 5 introduces the non-core Patient when it is an NP headed by a common noun, whether human or not:

\begin{tabular}{|c|c|c|c|c|}
\hline $\begin{array}{l}\mathrm{Nam}= \\
1 \mathrm{~s}: \mathrm{R}\end{array}$ & $\begin{array}{l}\text { vavere } \\
\text { sing }\end{array}$ & $\begin{array}{l}10 \\
\text { LOC }\end{array}$ & $\begin{array}{l}\text { vere } \\
\text { song }\end{array}$ & $\begin{array}{l}m o= \\
3: \mathrm{R}\end{array}$ \\
\hline
\end{tabular}

Note that the domains of use of $(i) n(i)$ and $l o$ intersect. When a common noun is [+human] [+specific], there is free variation in the choice of preposition, with no semantic difference (see also (46) below):

$\begin{array}{llll}\text { (23') } & \text { Nam }= & \text { lolokoru lo } & \text { rap̈ala-m. } \\ \text { 1s:R } & \text { be.angry LOC } & \text { friend-2s } \\ \text { ' } I \text { 'm angry at } & \text { your friend, }\end{array}$

'I'm angry at your friend.'

\section{DATIVE-MARKED PATIENTS}

Finally, some two-participants verbs encode $\mathrm{P}$ with the noun-like preposition ( $i$ )sa 'Dative'. Dative-marked Ps are always [+human] and they cannot be indexed on the verb.

\footnotetext{
${ }^{5}$ For an example of the same preposition used as a locative, see (5).
} 


$$
\begin{array}{llllll}
\text { Nra } & \text { mo }= & \text { re } & \text { ha }= & \text { v̈alum } & \text { isa-m̈am. } \\
\text { 3pl } & 3: \mathrm{R} & \text { say } & 3 \mathrm{p}: I r r & \text { fight } & \text { DAT-1ex:pl }
\end{array}
$$

'They want to fight with us.'

Dative-marked Ps are often associated with motion verbs. The spatial meaning can be literal or figurative: 6

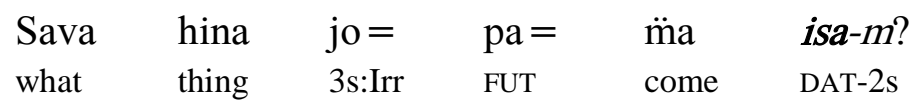

'What will happen to you?' [lit. what will come to you]

In a sentence like (26), the serialised motion verb sna 'come' is optional. In such a case, the dative-marked P can be analysed as an argument of 'speak', or of 'come', or of the whole construction:

$$
\begin{aligned}
& \mathrm{O}=\mathrm{pa}=\mathrm{le}=\text { sorosoro }(\mathrm{jo}=\text { sna }) \text { sa-ku ngisa? } \\
& \text { 2s:Irr FUT again speak (3s:Irr come) DAT-1s when } \\
& \text { 'When will you talk to me again?' [lit. you talk it comes to me when?] }
\end{aligned}
$$

\subsection{Summary}

Table 4 summarises the various ways in which two-participant clauses encode their Patients in

\begin{tabular}{|c|c|c|c|}
\hline nature of $P$ & OBJECT & $O B L / L O C$ & DATIVE \\
\hline pronoun & $\mathrm{A}=\mathrm{V}-\mathbf{P}_{\mathrm{SFX}}$ & $\mathrm{A}=\mathrm{V} \quad(i) n i-\mathbf{P}_{\mathrm{SFX}}$ & $\mathrm{A}=\mathrm{V}(i) s a-\mathbf{P}_{\mathrm{SFX}}$ \\
\hline proper noun & \multirow{3}{*}{$\mathrm{A}=\mathrm{V} \quad \mathbf{P}_{\mathrm{NP}}$} & & \multirow{3}{*}{$\mathrm{A}=\mathrm{V}(i) \operatorname{sa}-n \mathbf{P}_{\mathrm{N}}$} \\
\hline common noun [+human] [+spec] & & $\mathrm{A}=\mathrm{V}(i) n(i) \mathbf{P}_{\mathrm{NP}}$ & \\
\hline common noun [+human] [-spec] & & \multirow[t]{2}{*}{$\mathrm{A}=\mathrm{V}$ lo $\mathbf{P}_{\mathrm{NP}}$} & \\
\hline common noun [-human] & $\mathrm{A}=\mathrm{V}$-AGR $\mathbf{P}_{\mathrm{NP}}$ & & - \\
\hline
\end{tabular}
Araki. In each box, ' $A=$ ' refers to the subject-and-mood proclitic (Table 1) that precedes the verb; $\mathrm{P}$ refers to the Patient argument, whether it takes the form of a suffix $\left(\mathrm{P}_{\mathrm{SFX}}\right)$ or a full NP $\left(\mathrm{P}_{\mathrm{NP}}\right)$. The dotted line in the middle column indicates that there is free variation between two strategies for that specific configuration [see (23)-(23')].

Table 4: Summary: Morphosyntax of Patients in monotransitive clauses

\footnotetext{
${ }^{6}$ The connection between [+human] locative markers and dative is found elsewhere in the area: cf. Mwotlap hiy (François 2003:19). Of course, datives commonly originate in spatial markers: cf. Eng. to; Spanish $a$ <Lat. $a d$, etc. (Heine and Kuteva 2002:37).
} 


\section{The Encoding Of Themes and Goals in Three-Participant Constructions}

As stated in the introduction, I call ditransitive verbs those verbs which subcategorise for three participants: one agent (A) and two other arguments, called the Theme (T) and the Goal (G). Throughout the following sections, bold typeface in examples will highlight the Theme.

The previous section on two-participant events showed that a patient-like participant $\mathrm{P}$ could be expressed as a core argument; as an oblique or locative; or as a dative argument. Crucially, a verb can have no more than one argument on any of these positions. This means that a threeparticipant verb in Araki cannot encode its two non-agent participant as two equally ranked objects in a double object construction; in other words, ditransitive alignment in this language cannot be of the neutral type (\$1.1). Only one of these two arguments $\mathrm{T}$ and $\mathrm{G}$ can access the syntactic status of object. As we will see, the competition is sometimes won by $\mathrm{T}$, sometimes by G. In each case, the argument that did not make it to the object slot is given a peripheral status, in the form of a prepositional phrase - whether oblique or dative.

\subsection{Two classes of three-participant verbs}

Three-participant verbs in Araki can be classified into two classes, depending on how they map semantic roles onto syntactic functions. The first class shows fixed mapping of its arguments onto syntactic functions; the second class shows regular alternation between two patterns.

\section{FIXED MAPPING}

Some verbs do the mapping in a fixed way, with no syntactic variation. They all show indirective alignment (\$1.1), insofar as they treat the Theme as a syntactic object, in the sense defined in §3.1. In other words, these verbs always align $\mathrm{T}$ with the core-argument $\mathrm{P}$ of default twoparticipant constructions.

An example of a lexical item with fixed mapping is sohani 'send'. Examples (27) and (28) show that $\mathrm{T}$ is always the object, regardless of its referential properties such as animacy or humanness.

$\begin{array}{lllll}\mathrm{Na}= & \mathrm{pa}= & \text { sohani-ko } & \text { sa- } \boldsymbol{F} & \text { ram̈a-ku. } \\ 1 \mathrm{~s}: I r r & \text { FUT } & \text { send-2s:OBJ } & \text { DAT-CSTR } & \text { father-1s }\end{array}$

'I'll send $\mathbf{y o u}_{\mathbf{T}}$ to my father.'

$\begin{array}{lllllll}\mathrm{Na}= & \mathrm{pa}= & \text { sohani-a } & \text { leta } & \mathrm{mo}= & \text { hese } & \text { isa- } m . \\ 1 \mathrm{~s}: \mathrm{Irr} & \text { FUT } & \text { send-3s:OBJ } & \text { letter } & 3 \mathrm{~s}: \mathrm{R} & \text { one } & \text { DAT-2s }\end{array}$

'I'll send a letter ${ }_{\mathrm{T}}$ to you.'

For these verbs, the Goal $\mathrm{G}$ is encoded as a non-core complement. If $\mathrm{G}$ refers to a location (as per the broad definition given of $\mathrm{G}$ in $\S 1.2$ ), it takes the form of a locative phrase. If it is a place name, it is constructed directly; if it is a common noun, it is introduced by the locative preposition $l o$ : 

$\mathrm{Kam}=$ sohani-ko Vila.
1exc.pl:R send-2s:OBJ (place)
'We're sending you to Port Vila.'

Kam $=\quad$ sohani-ko $\quad$ lo $\quad$ skul.
1exc.pl:R
send-2s:OBJ $\quad$ LOC
'Wehool

If the goal $\mathrm{G}$ is human, the preposition used is $(i)$ sa- 'DATIVE', as in (27) and (28).

Other examples of verbs belonging to this class include rusan 'release, give away' and hashaso 'praise, recommend':

\begin{tabular}{|c|c|c|c|c|c|}
\hline $\begin{array}{l}\mathrm{Nam}= \\
1 \mathrm{~s}: \mathrm{R}\end{array}$ & $\begin{array}{l}\text { rusan } \\
\text { release }\end{array}$ & $\begin{array}{l}\text { venar̄u-ku } \\
\text { daughter-1s }\end{array}$ & $\begin{array}{l}(\mathrm{mo}= \\
3: \mathrm{R}\end{array}$ & $\begin{array}{l}\ddot{\mathrm{va}}) \\
\text { go }\end{array}$ & $\begin{array}{l}\text { isa-m. } \\
\text { DAT-2s }\end{array}$ \\
\hline
\end{tabular}

$$
\begin{aligned}
& \mathrm{Mo}=\text { hashaso lamane ne sa-ku. } \\
& \text { 3:R praise boy that DAT-1s } \\
& \text { 'They recommended that boy to me.' }
\end{aligned}
$$

As is frequently the case with Datives (see §3.2), the main verb is optionally followed by a serialised directional verb (see also (31)):

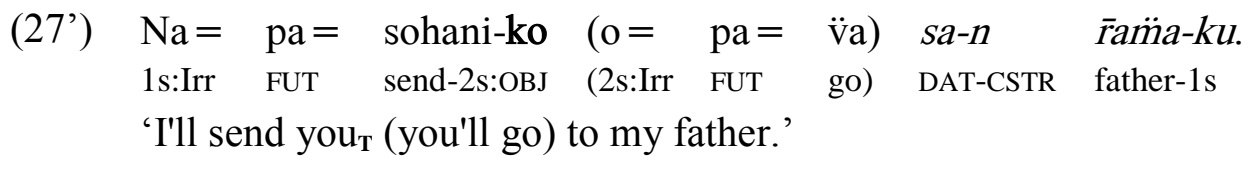

It could be a matter of debate whether the dative arguments of (31) and (27') are really arguments of the first verb ( $\overline{r u s a n}$, sohani), or of the directional verb that follows. One reason to support the first of these two hypotheses is that the motion verb is optional; and even when it is absent, the dative argument is required. In other words, the main verb subcategorises for A, T and G. Following a serialising pattern which is highly productive in Araki (François 2002: 193) and in other Oceanic languages (cf. Margetts 2007:91), this main verb is typically followed by a directional verb (go, come, descend...), which in turn subcategorises for a subject $\mathrm{S}$ and a goal $\mathrm{G}$. This is simply a case of argument sharing in a serial verb construction, and should not change the analysis of rusan and sohani as three-participant verbs. The directional verb does not bring any new participant to the clause, which explains its optional status in Araki.

\section{DIFFERENTIAL MAPPING}

Among the set of three-participant verbs, three lexical verbs show regular variation with regard to whether $\mathrm{T}$ or $\mathrm{G}$ is the object. These verbs are: 


$$
\begin{array}{lll}
\text { - } & \operatorname{sle}(i) & \text { 'give s.t./s.o. to s.o.' } \\
\text { - vse }(i) & \text { 'show } \sim \text { teach s.t./s.o. to s.o.' } \\
\text { — } & \text { varai } & \text { 'mention } \sim \text { reveal s.t./s.o. to s.o.; tell s.o. s.t.' }
\end{array}
$$

For these three verbs, the Goal is always human (or treated as such: see §4.4.3). The prototypical configuration is that the Theme is [-human]. This is by far the most frequent in natural discourse: in my 1997 corpus of spontaneous speech, out of 26 clauses featuring these verbs, 24 had a [-human] theme, i.e. $92.3 \%$.

In that prototypical case, the rule is that the semantic Goal has object status, while the Theme appears in a prepositional phrase - either with oblique $(i) n(i)$ or locative $l o$, following the same rules as oblique Patients (cf. §3.2). This pattern, known as secundative alignment ( 1.1$)$, is illustrated in (33) and (34):

$$
\begin{aligned}
& \langle\text { Naivou-ku }\rangle_{\mathrm{A}} \text { mo }=\text { sle }\langle\text { mara variri }\rangle_{\mathrm{G}}\langle\mathbf{l o} \text { hanhan }\rangle_{\mathrm{T}} . \\
& \text { wife-my } 3: \mathrm{R}=\text { give child small:PL } \mathrm{LOC} \text { food } \\
& \text { 'My wife has given the kids their food.' }
\end{aligned}
$$

$$
\begin{aligned}
& \mathrm{Na}=\quad \mathrm{pa}=\text { varai } \mathrm{Ta}_{\mathrm{G}}\langle\text { ini }-\mathbf{a}\rangle_{\mathrm{T}} \text {. } \\
& 1 \mathrm{~s}: I r r=\text { FUT tell Dad OBL-3s } \\
& \text { 'I'll tell Dad about it.' }
\end{aligned}
$$

In this particular context, the reverse alignment would be ungrammatical:

$$
\begin{aligned}
& { }^{*} N a=p a=\operatorname{varai}_{-a_{\mathrm{T}}}\langle s a-n \quad T a\rangle_{\mathrm{T}} . \\
& \text { 1s:Irr= FUT tell-3s:OBJ DAT-CSTR Dad } \\
& \text { *'I'll tell Dad about it.' }
\end{aligned}
$$

While the indirective alignment is the only one possible for the verbs showing fixed mapping $(\S 4.1)$, the three verbs sle $(i)$, vse $(i)$ and varai have the particularity to alternate between secundative $($ Object $=\mathrm{G})$ and indirective $($ Object=T) alignment.

The way these same verbs form Indirective alignment is formally parallel to what we saw in (27)-(28) above: $\mathrm{T}$ is the object, and $\mathrm{G}$ appears in a prepositional phrase using Dative $(i) s a$ :

$$
\begin{aligned}
& \mathrm{Na}=\mathrm{pa}=\text { sle } \quad-\mathrm{ko}_{\mathrm{T}} \quad s a-n \quad \text { ran̈a }_{\overline{\mathrm{r}}}{ }_{\mathrm{G}} \text { ! } \\
& \text { 1s:Irr= FUT give }-2 \mathrm{~s} \text { :OBJ DAT-CSTR monster }
\end{aligned}
$$

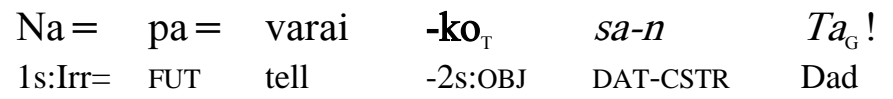

'I'll tell Dad about you.'

In this particular context, the reverse alignment would be ungrammatical: 


$$
\begin{aligned}
& \text { *Na= pa= varai } \mathrm{Ta}_{G}\langle\text { ini-ko }\rangle_{\mathrm{T}} . \\
& \text { 1s:I= FUT tell Dad } \mathrm{OBL}-2 \mathrm{~s} \\
& \text { *'I'll tell Dad about you.' }
\end{aligned}
$$

In sum, these three verbs show variation in the way they assign syntactic functions to their nonagent participants:

— sometimes the object is $\mathrm{G}$ [secundative alignment], while $\mathrm{T}$ is encoded as an oblique phrase, using $(i) n(i)$ or $l o$;

- sometimes the object is $\mathrm{T}$ [indirective alignment], while $\mathrm{G}$ is encoded as a dative phrase, using $(i) s a$.

According to Jauncey (2010:245), the neighbouring language Tamambo shows free variation between the two strategies, for the same verbs. By contrast, Araki shows grammatical restrictions on which strategy should be used, depending on the nature of its arguments.

François $(2002: 161)$ pointed out the key role played in this alternation by the criterion of humanness of the Theme:

- If the Theme is [-human] as in (33), it is encoded as an oblique argument while the Goal is a core argument.

- If the Theme is [+human] as in (35), it is treated as a core argument, while the Goal is encoded as a dative.

In other terms, Araki takes into account the humanness of its non-agent participants in the coding not only of two-participant constructions (§3.3) but also of those with three participants - even though the application and effect of this semantic factor are distinct in the two construction types.

\subsection{A referential hierarchy}

While the analysis in terms of humanness fit well with the initial corpus I had collected in 1997, new research conducted in 2011 revealed that this feature is not the only criterion that underlies the syntactic alternation of the three ditransitive verbs sle(i), vse(i) and varai. The second ingredient is the hierarchy of PERSON - more precisely, the contrast between the speech act participants or local persons (i.e. $1^{\text {st }}$ and $2^{\text {nd }}$ person) and the non-local (i.e. $3^{\text {rd }}$ ) person referents (Andrews 2007).

The person scale can be formulated as in $\langle\mathrm{H} 1\rangle$ :

$$
\text { [+local } \left.] \text { person }\left(1^{\text {st }} \text { or } 2^{\text {nd }}\right)>\text { [-local }\right] \text { person }\left(3^{\text {rd }} \text { person }\right)
$$

Because the whole scale $\langle\mathrm{H} 1\rangle$ involves human referents, it can easily be combined with the contrast in humanness, in the form of the referential hierarchy $\langle\mathrm{H} 2\rangle$ :

$$
[+ \text { human }][+ \text { local }]>[+ \text { human }][\text {-local }]>[\text {-human }]
$$


The hierarchy that obtains, based on person and animacy, is consistent with the referential hierarchies developed in linguistic typology since Silverstein (1976), which are the object of the present volume.

As the evidence below will show, the criteria determining the alignment of three-participant constructions in Araki are not the referential properties of $\mathrm{T}$ alone, but their relative position with respect to $\mathrm{G}$ on the referential hierarchy $\langle\mathrm{H} 2\rangle$. Specifically, I claim that the choice of construction is governed by the following rules:

(37) If $\mathrm{G}$ ranks higher than $\mathrm{T}$ on the referential hierarchy, then $\mathrm{G}$ is the object, and $\mathrm{T}$ is encoded as an oblique.

(38) If $\mathrm{T}$ ranks higher than $\mathrm{G}$ on the referential hierarchy, then $\mathrm{T}$ is the object, and $\mathrm{G}$ is encoded as a dative.

Or, to put it more simply:

(39) The participant ranking higher on the referential hierarchy $\langle\mathrm{H} 2\rangle$ has the status of object; the other participant is encoded as a peripheral argument.

Incidentally, because it never happens that both $\mathrm{G}$ and $\mathrm{T}$ are [-human], a corollary of (39) is that the object of these three ditransitive verbs is always [+human]. This contrasts with a fixedmapping verb such as send, whose object is sometimes inanimate as in (28) above.

Compared to François (2002) which had defined the importance of the feature [human], the principal finding of the 2011 follow-up research was to highlight also the role played by the feature [local], and place the referential hierarchy $\langle\mathrm{H} 2\rangle$, together with the rule (39), at the heart of the system.

Section 4.3 will examine those cases when $\mathrm{T}$ and $\mathrm{G}$ have different ranking on the referential scale $\langle\mathrm{H} 2\rangle$; we shall see that the principle (39) is then always verified. In turn, Section 4.4 will address cases when $\mathrm{T}$ and $\mathrm{G}$ have equal ranking, and see that no systematic principle can then be identified. Each in its own way, these two configurations will confirm the validity of the referential hierarchy.

\subsection{When $T$ and $G$ have different ranking}

I will begin with cases in which $\mathrm{T}$ is higher than $\mathrm{G}$ on the $\langle\mathrm{H} 2\rangle$ scale. In a configuration like show you to him, $\mathrm{T}$ is $2^{\text {nd }}$ person, while $\mathrm{G}$ is $3^{\text {rd }}$ person. In this case, $\mathrm{T}$ ranks higher than $\mathrm{G}$, and therefore is the object:

$$
\begin{aligned}
& \mathrm{Na}=\mathrm{pa}=\text { vsei } \text {-ko }_{\mathrm{T}}\left\langle\begin{array}{lll}
\text { sa-n } & \mathrm{Ta}\rangle_{\mathrm{G}} .
\end{array}\right. \\
& 1 \mathrm{~s}: \mathrm{I}=\text { FUT show }-2 \mathrm{~s}: \text { OBJ DAT-CSTR Dad }
\end{aligned}
$$

$$
\begin{array}{lllll}
\mathrm{O}= & \text { kan } & \text { slei } & -\mathbf{a}_{\mathrm{T}} & \langle\text { sa-na }\rangle_{\mathrm{G}} ! \\
2 \mathrm{~s}: \mathrm{I}= & \text { PROH } & \text { give } & -1 \mathrm{~s}: \text { OBJ } & \text { DAT-3s }
\end{array}
$$

'Don't give me to him!' 
The reverse alignment would be ungrammatical:

$$
\begin{array}{ccccc}
* N a= & p a= & \text { VSe } & T_{G} & \langle\text { ini-ko }\rangle_{\mathrm{T}} \\
\text { 1s:I }= & \text { FUT } & \text { show } & \text { Dad } & \text { OBL-2s } \\
& & & & \\
* O= & \text { kan } & \text { slei } & -a_{G} & \langle\text { ini-âa }\rangle_{\mathrm{T}} \\
\text { 2s:I } & \text { PROH } & \text { give } & -3 \mathrm{~s}: \text { OBJ } & \text { OBL-1s }
\end{array}
$$

Examples like (40), or (35) above, were initially explained by the tentative hypothesis that a human Theme is automatically promoted to object position. However, if the referential values of $\mathrm{T}$ and $\mathrm{G}$ are reversed, as in (42), $\mathrm{G}$ becomes the object. Indeed, even though $\mathrm{T}$ is [+human], it is non-local $\left(3^{\text {rd }}\right.$ person) while $\mathrm{G}$ is local $\left(2^{\text {nd }}\right.$ person). Because $\mathrm{G}$ ranks higher than $\mathrm{T}$ on the referential hierarchy $\langle\mathrm{H} 2\rangle$, it has object status, and $\mathrm{T}$ remains prepositional:

$$
\begin{aligned}
& \mathrm{Na}=\mathrm{pa}=\text { vsei }-k \boldsymbol{o}_{\mathrm{G}} \quad\langle\text { ini-a }\rangle_{\mathrm{T}} . \\
& \text { 1s:I= FUT show }-2 \mathrm{~s}: \mathrm{OBJ} \\
& \text { 'I will show him to you.' }
\end{aligned}
$$

As the following examples show, $\mathrm{T}$ is introduced sometimes by the oblique preposition $(i) n(i)$, sometimes by the locative $l o$, in exactly the same conditions as defined earlier with oblique Patients (see $\$ 3.3$ ).

$$
\begin{array}{llllll}
\mathrm{Om}= & \text { je } & \ddot{\text { mis }} & \text { varai } & \text {-á } & \langle\text { ini-a }\rangle_{\mathrm{T}} . \\
2 \mathrm{~s}: \mathrm{R}= & \text { NEG } & \text { yet } & \text { tell } & -1 \mathrm{~s}: \text { OBJ } & \text { OBL-3s }
\end{array}
$$

'You haven't told me yet about her.'

$$
\rightarrow[+ \text { pronoun }]
$$

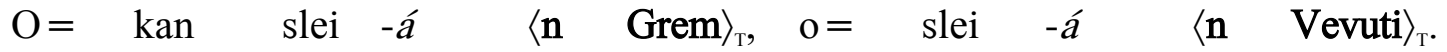
$2 \mathrm{~s}: \mathrm{I}=\mathrm{PROH}$ give $-1 \mathrm{~s}: \mathrm{OBJ}$ OBL G. $2 \mathrm{~s}: \mathrm{I}=$ give $-1 \mathrm{~s} . \mathrm{OBJ}$ OBL V. (child adoption) 'Don't give me Graham, give me Vevuti.'

$\rightarrow[+$ proper noun $]$

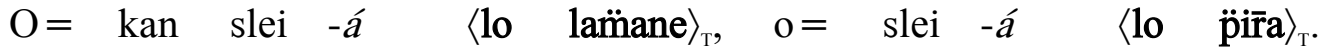

$$
\begin{aligned}
& 2 \mathrm{~s}: \mathrm{I}=\mathrm{PROH} \text { give }-1 \mathrm{~s}: \text { OBJ LOC male 2s:I= give }-1 \mathrm{~s} . \mathrm{OBJ} \text { LOC female }
\end{aligned}
$$

'Don't give me a boy, give me a girl.'

$$
\rightarrow \text { [+common noun] [+human] [-specific] }
$$

Just like we saw for (23)-(23') above, there is free variation between the two prepositions when, and only when, $\mathrm{T}$ is a common noun that is both human and specific:

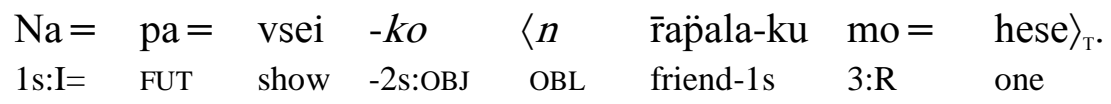




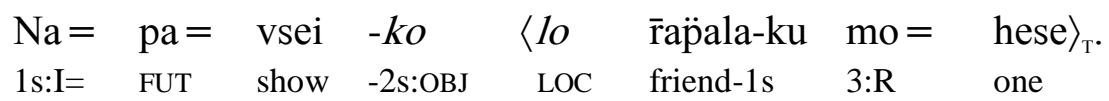

'I will show you one of my friends.'

$$
\rightarrow[+ \text { common noun] [+human] [+specific }]
$$

Overall, when the person values of the two non-agent participants involve a contrast between a local and a non-local person, the results are robust. The LOCAL person (whether it is the Theme or the Goal) takes priority for the syntactic status of object, while the non-local person is expressed in a prepositional phrase. Swapping the person values of $\mathrm{T}$ and $\mathrm{G}$ entails a change of alignment, so as to respect the hierarchy $\{$ LOCAL $>$ NON-LOCAL $\}$ :

$$
\begin{aligned}
& \mathrm{O}=\quad \mathrm{pa}=\text { vsei } \quad-\mathbf{a}_{\mathrm{T}} \quad\langle\text { sa-na }\rangle_{\mathrm{G}} \text { ? } \\
& 2 \mathrm{~s}: \text { Irr }=\text { FUT show }-1 \mathrm{~s} \text { :OBJ DAT-3s } \\
& \text { 'Will you show me to her?' }
\end{aligned}
$$

$$
\begin{aligned}
& \mathrm{O}=\quad \mathrm{pa}=\text { vsei } \quad-a_{\mathrm{G}} \quad\langle\text { ini-a }\rangle_{\mathrm{T}} \text { ? } \\
& 2 \mathrm{~s}: \text { Irr }=\text { FUT show }-1 \mathrm{~s} \text { :OBJ OBL-3s } \\
& \text { 'Will you show her to me?' }
\end{aligned}
$$

As was already clear from the initial description of the alternation pattern (§4.1), the results are also robust when the two non-agent participants differ in humanness. Given that $\mathrm{G}$ is necessarily [+human] with sle(i), vse $(i)$ and varai (\$4.1.2), the only case when such discrepancy occurs is when $\mathrm{T}$ is [-human]; this case always triggers secundative alignment:

$$
\begin{array}{llllll}
\mathrm{O}= & \text { vsei } & -\mathrm{a}_{\mathrm{G}} & \langle\text { lo } & \text { pla-m } & \text { to }\rangle_{\mathrm{T}} !^{\prime} \\
\text { 2s:I= } & \text { show } & -1 \mathrm{~s}: \text { OBJ } & \text { LOC } & \text { FARMING-2s } & \text { chicken }
\end{array}
$$

'Show me your chickens!'

$$
\begin{aligned}
& \mathrm{O}=\text { slei }-a_{\mathrm{G}} \quad\langle\text { ini-a }\rangle_{\mathrm{T}} \text { ! } \\
& 2 \mathrm{~s}: \mathrm{I}=\text { give }-1 \mathrm{~s}: \mathrm{OBJ} \text { OBL-3s } \\
& \text { 'Give it to me!' }
\end{aligned}
$$

Finally, while (47') above confirmed that a [+human] [-local] participant (here 'her') ranks lower than a local person, (50) shows it ranks higher than a [-human] referent.

$$
\begin{aligned}
& \mathrm{O}=\quad \mathrm{pa}=\text { vsei } \quad-\mathrm{a}_{\mathrm{G}} \quad\langle\text { ini-a }\rangle_{\mathrm{T}} \text { ? } \\
& \text { 2s:Irr }=\text { FUT show }-3 \mathrm{~s} \text { :OBJ OBL-3s } \\
& \text { 'Will you show it to her?' }
\end{aligned}
$$

Even though both suffixes $/-a /$ refer to a $3^{\text {rd }}$ person and could therefore be ambiguous, the oblique preposition ini can only introduce the Theme in a secundative construction, and this entails that the verb's object is the Goal. In other words, [+human] [-local] participants have a medial position in the referential scale, as represented in the scale $\langle\mathrm{H} 2\rangle$ above. 


\subsection{When $T$ and $G$ have equal ranking}

Whenever $\mathrm{T}$ and $\mathrm{G}$ belong to two distinct categories on the hierarchy $\langle\mathrm{H} 2\rangle$, speakers show virtually no hesitation or variation; the observed correlations are systematic. But what happens when the two arguments belong to the same category?

Before addressing this point, I should emphasise that the relevant data are based on a limited corpus, and on elicitation. The possibility of testing these configurations with natural data was hampered by their rarity in spontaneous speech and in narrative corpora (\$4.1). First, human themes in three-participant constructions are extremely rare, and show seldom in spontaneous discourse. Second, the alignment alternation concerns only three verbs, and among these, the verb sle 'give' was reluctantly accepted in combination with human Themes - speakers idiomatically prefer to use rusan 'release' (\$4.1) for when a person is being "given" to someone, as in marriage arrangements or adoption practices. Combining sle 'give' with a human theme was thus unnatural in the first place, which made it difficult to test these constructions in natural discourse. The verbs vsei 'show' and varai 'tell' are more commonly used with human Themes, but still it was often necessary to resort to elicitation, rather than observe spontaneous speech in actual use. Finally, the peculiar situation of endangerment which characterises Araki also leaves few opportunities for natural conversation to be recorded. It was therefore impossible to conduct any quantitative study based on frequency, or to observe such parameters as topicality or discourse saliency in a natural corpus. Judgments given by speakers, assessing the grammaticality and naturalness of each construction, had to be given full weight.

\section{TWO LOCAL PERSONS}

When the two arguments are local persons, i.e. speech-act participants, free variation is observed. Both the secundative and the indirective alignments are accepted:

\begin{tabular}{|c|c|c|c|c|c|c|}
\hline 51) & $\begin{array}{l}\text { Rapaala-ku } \\
\text { friend-1s }\end{array}$ & $\begin{array}{l}\mathrm{mo}= \\
3: \mathrm{R}=\end{array}$ & $\begin{array}{l}\text { je } \\
\text { NEG }\end{array}$ & $\begin{array}{l}\text { varai } \\
\text { tell }\end{array}$ & $\begin{array}{l}-\mathbf{k} \mathbf{o}_{\mathrm{T}} \\
-2 \mathrm{~s}: \mathrm{OBJ}\end{array}$ & $\begin{array}{l}\langle\text { isa-ku }\rangle_{\mathrm{G}} . \\
\text { DAT-1s }\end{array}$ \\
\hline & \multicolumn{6}{|c|}{ 'My friend never mentioned you to me.' } \\
\hline & $\begin{array}{l}\text { Rapäala-ku } \\
\text { friend-1s }\end{array}$ & $\begin{array}{l}\mathrm{mo}= \\
3: \mathrm{R}=\end{array}$ & $\begin{array}{l}\text { je } \\
\text { NEG }\end{array}$ & $\begin{array}{l}\text { varai } \\
\text { tell }\end{array}$ & $\begin{array}{l}-a_{\mathrm{G}} \\
-1 \mathrm{~s}: \mathrm{OBJ}\end{array}$ & $\begin{array}{l}\langle\text { ini-ko } \\
\text { OBL-2s }\end{array}$ \\
\hline
\end{tabular}

'My friend never told me about you.'

This suggests that Speaker and Addressee do not enter in any absolute hierarchy with each other.

Another sign that there is no fixed hierarchy between the two speech act participants is that the choice of construction can be sensitive to "syntactic priming" effects (cf. Branigan et al. 1995). Thus in (52), the fact that the reply shows secundative alignment is presumably due to the use of that same construction in the question:

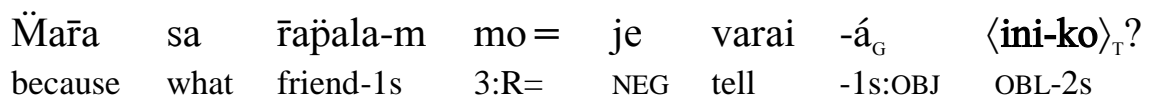

'Why hasn't your friend ever told me about you?' 
contrasts with the sharp asymmetry observed when the Theme is [-human]:
Mara sa om $=$ je vsei ram̈a-m $\mathrm{G}_{\mathrm{G}} \quad\langle\text { in } \quad \text { rap̈ala-m }\rangle_{\mathrm{T}}$ ?
because what $2 \mathrm{~s}: \mathrm{R}=\mathrm{NEG}$ show father-2s OBL friend-2s
'Why don't you show your father your friend?'

$\begin{array}{llllllll}\ddot{M} a \bar{r} a & \text { sa } & \text { om }= & \text { je } & \text { vsei } & \text { rap̈ala-m } & \langle\text { sa-n } & \text { ram̈a-m }\rangle_{\mathrm{G}}\end{array}$ ?

'Why don't you show your friend to your father?'

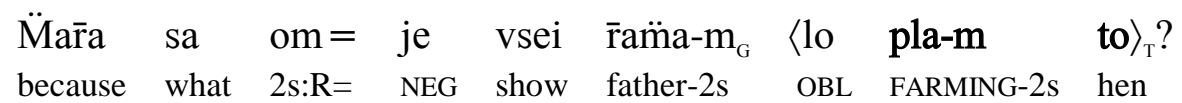

'Why don't you show your father your chickens?'

* Mara sa $\quad$ om $=$ je vsei-a pla-m to ${ }_{\mathrm{T}}\langle s a-n \quad \text { ran̈a-m }\rangle_{\mathrm{G}}$ ?

because what $2 \mathrm{~s}: \mathrm{R}=$ NEG show-3s FARMING-2s hen DAT-CSTR father-2s

* 'Why don't you show your chickens to your father?'

Even though both alignments are accepted in elicitation - as in (53)-(56) - it is possible that the choice of one construction over the other, in natural discourse, may involve such dimensions as discourse topicality, rhythmic weight, or other factors. However, these questions have proved difficult to test, for reasons mentioned above. Under elicitation, both the secundative and indirective constructions were judged equally grammatical, and even equally natural; as for corpus examples, they were too few to make general statements.

This being said, the observation of naturally occurring utterances seems to indicate a slight preference in favor of indirective alignment with human Ts, as in (58):

$\begin{array}{lllllll}\text { Rasi-ku } & \mathrm{mo}= & \text { sle } & \text { naru-na } & \langle\text { sa-n } & \text { pira } & \text { nohoni }\rangle_{\mathrm{G}} . \\ \text { brother-1s } & 3: \mathrm{R}= & \text { give } & \text { son-3s } & \text { DAT-CSTR } & \text { woman } & \text { that }\end{array}$

'My brother gave his child to that woman.' [i.e. he got her pregnant]

This tendency has an interesting corollary. In the case of anaphoric reference using pronouns, it is often possible for the hearer to calculate the animacy of the Theme not by the form of the pronoun itself (since there is a single 3s pronoun $-a$ ' $\mathrm{him} / \mathrm{her} / \mathrm{it}$ ') but based on the choice of the construction - as in (50) above. In a sentence like (59), for example, the use of the indirective construction entails that the Theme is equal or superior to the Goal on the saliency hierarchy, which means it has to be [+human]:

$$
\begin{array}{lllll}
\mathrm{O}= & \text { kan } & \text { varai } & -\mathbf{a}_{\mathrm{T}} & \langle\text { sa-na }\rangle_{\mathrm{G}} \text { ! } \\
\text { 2s:I= } & \text { PROH } & \text { tell } & -3 \mathrm{~s}: \text { OBJ } & \text { DAT-3s }
\end{array}
$$

'Don't tell $\operatorname{him}_{i}$ about him $/$ /her.' [*about it ]

$$
T \text { is core, } G \text { is peripheral } \rightarrow \text { Theme is necessarily [+human] }
$$

The secundative construction, even though it could in principle refer to the same situation (two 
human participants), is typically reserved for cases when the Theme is [-human]:

$\begin{array}{llllll}\left(59^{\prime}\right) & \mathrm{O}= & \text { kan } & \text { varai } & -\mathrm{a}_{\mathrm{G}} & \langle\text { ini-a }\rangle_{\mathrm{T}} \text { ! } \\ & \text { 2s:I } & \text { PROH } & \text { tell } & -3 \mathrm{~s}: \text { OBJ } & \text { OBL-3s }\end{array}$

'Don't tell him about it.' [??about him/her]

$T$ is peripheral, $G$ is core $\rightarrow$ Theme is most probably [-human]

Araki thus favours indirective alignment as the default construction when dealing with human themes, because it is a semantically unambiguous strategy. This preference is found even when $T$ has low individuation, as in this negative sentence where $\mathrm{T}$ is marked as [-specific]:

$$
\begin{array}{llllll}
\mathrm{Na}= & \mathrm{pa}= & \text { je } & \text { sle } & \overline{\mathbf{r e}}_{\mathrm{T}} & \langle\text { sa-na }\rangle_{\mathrm{G}} . \\
1 \mathrm{~s}: I r r & \text { FUT } & \text { NEG } & \text { give } & \text { any } & \text { DAT-3s }
\end{array}
$$

'I won't give her any (child).'

This can be compared with cases when the Theme is [-specific] and [-human]:

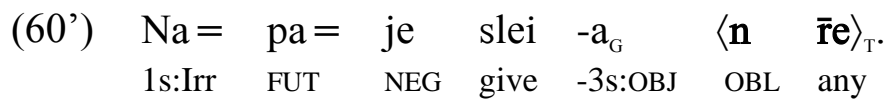

'I won't give her any (money).'

\section{NON-HUMAN GOALS?}

I mentioned in $\S 4.1$ that the recipient of sle 'give', varai 'tell' and vse 'show' is invariably [+human]. One reason for this is that the three actions normally involve sentient participants, which are normally human.

Only few animals are present in the traditional environment of Araki speakers: mostly birds, sea creatures, hunting game; farm-raised pigs and chickens; wild dogs. None of these belong to the social realm of humans, in the way pets, for example, do in other cultures. The only case when these ditransitive verbs are attested with animal recipients is in children stories whose heroes are animals:

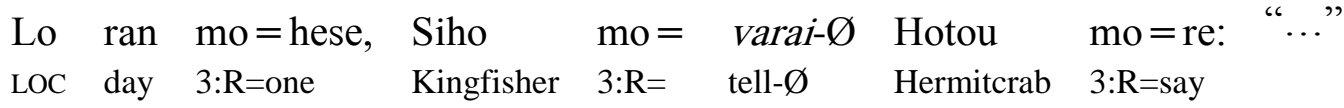

$$
\begin{aligned}
& \text { 'One day, Kingfisher told Hermitcrab: “..." }
\end{aligned}
$$

In (61), the Theme is the reported speech that follows the clause, and the Goal is a hermitcrab. Even though the latter is non-human, it is here treated formally like a human object, as is shown by the absence of agreement marker on the verb: compare the zero of (61) with (14)-(15) above. This belongs to a more general pattern of personification, whereby animal heroes in stories take up the morphosyntactic properties (accusative marking, genitive marking, determiners, etc.) which are normally reserved, in ordinary speech, to human referents (François 2002:97, 142). In other words, (61) is not a genuine instance of a [-human] recipient, because it appears in a context where animals are commonly recategorised as human anyway.

The configuration in which a genuine animal (other than in stories) is a recipient of an event 
of transfer, as in give the dog a bone, is not attested in my narrative corpus, nor was it included in my elicitation data. For a similar context such as give some food to the pig, Araki spontaneously uses a monotransitive verb v̈ahani 'feed'. For these three verbs, all cases of recipients attested in my corpus involve sentient, human recipients.

The other question is whether a recipient can be inanimate altogether, as in Eng. 'give money to the bank'. When asked about this, speakers avoided the use of these ditransitive verbs. Instead, they preferred to use other verbs (like 'send' or 'put'), with a locative complement:

$$
\begin{aligned}
& \mathrm{Na}=\mathrm{pa}=\text { hureni-a no-k vatu }(\mathrm{jo}=\text { ro }) \text { lo pang. } \\
& \text { 1s:Irr FUT put-3s:OBJ POSs-1s money (3s:Irr= stay) LOC bank } \\
& \text { 'I'll place my money in the bank.' }
\end{aligned}
$$

Nonetheless, I was able to elicit just one case where the verb sle 'give' was accepted with an inanimate goal. The context given was 'give a child to the Church (as an institution) for adoption'. The construction chosen by the speakers was one in which the Goal, despite being inanimate, seems to rank higher than the Theme (children), insofar as it is treated as the object of a ditransitive construction (secundative alignment):

$$
\begin{array}{lllllll}
\text { Nană̄u-ku } & \text { mo=rua, nam }= & \overline{\mathrm{re}} & \text { sle- } \varnothing & \text { jej } & \langle\text { ni-ra }\rangle . \\
\text { children-1s } & 3: \mathrm{R}=\text { two } & 1 \mathrm{~s}: \mathrm{R}= & \text { PRF } & \text { give- } \varnothing & \text { church } & \text { OBL-3pl }
\end{array}
$$

'My two children, I've given them to the Church.'

There are two ways to interpret this unexpected result (63). One approach would be to analyse the recipient jej 'church' as a genuine [-human] recipient, and observe it ranks higher than a [+human] theme; this would force us to revise the model adopted until now to account for the syntactic distribution of $\mathrm{T}$ and $\mathrm{G}$. The second approach would propose that the recipient jej, despite its literal meaning, here "behaves as" a [+human] recipient. While the latter hypothesis has the advantage of rescuing the model, it may look, at first sight, like a circular argument: one cannot explain away an unexpected result by forcing it into a familiar yet different configuration. What we need is external evidence to establish whether the recipient jej 'church' here patterns with human or with non-human participants. Luckily, (63) provides the answer to this question, in the form of the agreement marking on the verb (\$3.1.2). If jej had its [-human] reading here, it would necessarily trigger agreement on the verb - as in (64):

$$
\begin{aligned}
& \begin{array}{lllll}
\mathrm{Mo}= & \text { je } & \text { lesi-a } & \text { jej } & \text { paro. } \\
3: \mathrm{R}= & \text { NEG } & \text { see-3s:OBJ } & \text { church } & \text { new }
\end{array} \\
& \text { * Mo }=\text { je lesi-Ø jej paro. } \\
& 3: \mathrm{R}=\quad \text { NEG see- } \varnothing \text { church new }
\end{aligned}
$$

'They haven't seen the new church.'

In a way similar to the case of animal personification (61), the absence of an agreement marker $/$-al in (63) sle (vs * slei-a) provides evidence, independent from the issue of ditransitive verbs, that the church is here treated grammatically as [+human]. This is partly due to the polysemy of the noun 'church', which may refer to a building as in (64) but also to a social institution as in 
(63). But it can also be argued that the transfer verb sle 'give', due to its privileged relationship with human recipients, has the effect, as it were, of reclassifying its recipient as human.

This observation, finally, is consistent with the choice of the secundative strategy, whereby 'church' ranks equal or higher than 'children' on the referential hierarchy. This confirms the earlier observation $(\$ 4.2)$ that the object of these ditransitive verbs is always [+human], even when it is only metaphorically so.

\section{Discussion}

\subsection{Summary of results}

To sum up, there are two classes of verbs expressing three-participant events in Araki. The first class, including sohani 'send', rusan 'release, give away', and hashaso 'praise, recommend', always shows indirective alignment, with $\mathrm{T}$ as the object, and $\mathrm{G}$ encoded in a dative prepositional phrase (\$4.1.1). The relevant constructions optionally involve the use of a serialised verb of motion. I will refer to this class as the 'send-class' in Figure 1 below.

The second class consists of the three ditransitive verbs: 'give', 'show' and 'tell'. The behaviour of these verbs rests on an underlying referential hierarchy, with three levels:

$\langle\mathrm{H} 2\rangle \quad$ [+human $][+$ local $]>[+$ human $][$-local $]>[$-human $]$

Table 5 summarises all the configurations examined in the previous sections, with the last column providing reference to numbered examples. The letter in bold refers to the participant (either G or T) which aligns formally with the Patient; as the table shows, it is always the one that ranks higher on the hierarchy. Rows with no bolded letter mean there is variation as to which participant becomes the object; the last row refers to a special case, in which an apparently nonhuman recipient was treated formally as if it were human.

\begin{tabular}{ccc|l}
\hline $\begin{array}{c}\text { [+human] } \\
\text { [+local] }\end{array}$ & $\begin{array}{c}\text { [+human] } \\
\text { [-local] }\end{array}$ & > [-human] & \multicolumn{1}{|c}{ examples } \\
\hline & $\mathbf{G}$ & $\mathrm{T}$ & $33-34,50,57,59$, \\
$\mathbf{G}$ & & $\mathrm{T}$ & $48-49$ \\
$\mathbf{G}$ & $\mathrm{T}$ & & $35-36,42-46^{\prime}, 47^{\prime}$, \\
$\mathbf{T}$ & $\mathrm{G}$ & $40-41,47$ \\
$\mathrm{~T}, \mathrm{G}$ & & $51-52$ \\
& $\mathrm{~T}, \mathrm{G}$ & & $53-56,59-60$ \\
& $\mathrm{~T}, \mathrm{G}$ & $\leftarrow(\mathrm{G})$ & 63 \\
\hline
\end{tabular}

Table 5: Mapping corpus examples onto the referential hierarchy

As Table 5 shows, the hierarchy between the three levels is robust. Should the two non-agentive participants belong to separate levels on this scale, the syntax of the clause will systematically reflect the hierarchy, by providing the higher-ranking non-agentive participant ( $T$ or $\mathrm{G}$ ) with the status of core argument (Object), and by expressing the lower-ranking one in a prepositional phrase. This results in a regular alternation between secundative and indirective alignments. When, however, the two participants belong to the same level (either two local persons, or two 
non-local persons), no clear hierarchy governs their syntactic behaviour. Both syntactic constructions are accepted.

The syntax of Araki three-participant verbs is synthesised in Figure 1, in the form of a decision chart.

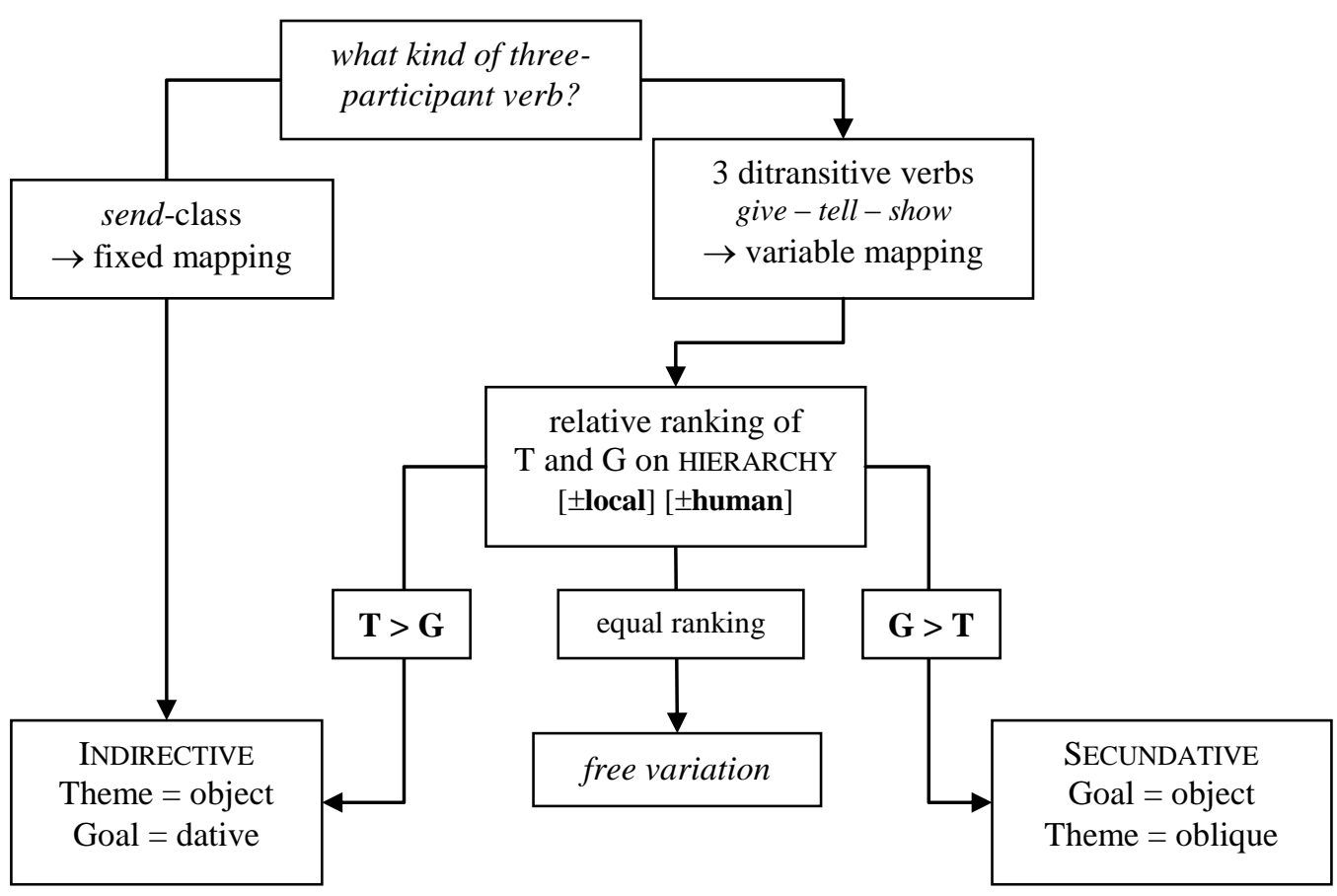

Figure 1: The syntax of three-participant verbs in Araki: a decision chart

A similar construction split is described for Jamul Tiipay, a Yuman language of California (Miller 2001:162). While the basic alignment of ditransitive verbs in Jamul Tiipay is secundative, "it can change to indirective if T outranks G on the person scale" (Malchukov et al. 2010). However, Araki differs from Jamul Tiipay in various aspects: by the absence of ranking between $1^{\text {st }}$ and $2^{\text {nd }}$ person; by the possibility of free variation between alignments in certain configurations; and by the existence of a verb class for which indirective alignment is the only one possible.

\subsection{Functional interpretation}

How can we interpret these results? Why do 'give', 'show' and 'tell' behave the way they do, and why do they behave differently from verbs of the send class?

\section{WHO'S AFFECTED?}

The morphosyntax of Araki ditransitive verbs is thus sensitive to two features of its non-agentlike participants: whether they are [ \pm human], and whether they are $[ \pm$ local], i.e. directly involved in the speech act. That participant which ranks higher on these two parameters combined will be the verb's object, i.e. align formally with prototypical Patients, whereas the other one will be given a peripheral, non-core function in the form of a prepositional phrase. 
Næss (2004; 2007), dealing with two-participant constructions, showed that Differential object marking (DOM) is best analysed in terms of affectedness. Highly individuated objects, i.e. definite or human or otherwise more salient participants, can be said to be more affected than less individuated ones (Næss 2004: 1202); in her interpretation, this parameter of affectedness is central to the characterisation of objects in a typically transitive clause. In the case of DOM, the contrast is between two kinds of objects, one more and one less individuated, with different degrees of affectedness.

I'd like to propose that the complex rules followed by Araki ditransitive verbs also involve degrees of affectedness. Yet instead of involving a contrast between two kinds of objects, the opposition stands here between two different participants, T and G. While the position of object, in this language, is in principle open both to the Theme and to the Goal, in a particular clause they have to compete as to which one will be selected to be the object. The main criterion for that competition is their relative degree of affectedness, i.e. which of those two participants is more like a prototypical object.

With transfer events like 'give', 'show' and 'tell', the typical configuration is one where the Theme is inanimate and the Goal is human. In this case, the sentient participant is the more affected and thus the foregrounded participant: this explains why this case will systematically results, in Araki, in the alignment of the Goal with the Patient of monotransitive clauses.

When both $\mathrm{T}$ and $\mathrm{G}$ are human, but one of them is a speech participant while the other is a $3^{\text {rd }}$ person, then the local one is more salient in discourse, and perceived as more affected, regardless of its semantic role. Thus if you show me to your cousin, the more salient participant (me) is the one placed on the foreground, and it will be coded as the object in Araki. If one swaps Theme and Goal (as in show me your cousin), the speech-act participant remains foregrounded, and from the point of view of the speaker the event is still semantically oriented towards himself. Here too, Araki will treat that local participant as more salient, and therefore better suited for the position of object - that is, for the morphosyntactic treatment that would align them with prototypical Patients.

Finally, when both the Theme and the Goal rank equally on the scale, it is in principle ambiguous which one will be more affected or foregrounded. If I show my girlfriend to my mother, will my action primarily affect my girlfriend, or my mother? Arguably, both the Theme and the Goal are equally affected in such a case (cf. Siewierska and Van Lier 2011). This is why they can equally claim the status of object in Araki, and show here free variation.

\section{TWO CLASSES OF THREE-PARTICIPANT VERBS}

Interestingly, Araki only makes this competition possible for certain verbs of transfer, but not for others. In an event such as send (s.th., s.o.), the only participant that will always be affected is the Theme, whether it is human or not. This is due to the fact that send refers to an event of caused motion, which does not necessarily entail that the target is reached: an utterance such as (28) I sent a letter to you can be true even if the letter never reached its recipient. With a verb like send, release or praise, the event is always construed from the perspective of the Theme; it is the only participant which can have access to the status of object. This explains why, in Araki, such verbs are excluded from the domain of ditransitive verbs for which the competition between $\mathrm{T}$ and $\mathrm{G}$ is open.

By contrast, the events expressed by the verbs sle 'give', varai 'tell' and vse 'show' all inherently entail the success of the transfer event. These three events encode not caused motion 
but caused possession (see Rappaport Hovav and Levin 2008) - whether literally in the case of 'give', or figuratively in the case of 'tell' and 'show': the main point is that events of giving, telling or showing, are only valid - at least in Araki - if the theme has entered the sphere, whether real or symbolic, of the recipient. In I gave her a present, the recipient is necessarily affected by the event, regardless whether the caused-possession event itself is successful strictly speaking - i.e. whether she did accept the gift or not. In order to be assigned any truth value, these three verbs inherently involve both a Theme and a Goal.

In sum, for any given three-participant verb in Araki, it is a requirement that potentially both $\mathrm{T}$ and $\mathrm{G}$ must be equally affectable for them to be able to compete for object status. In this language, this lexical precondition is only met by three verbs ('give', 'tell' and 'show'); these are the only verbs concerned by the syntactic competition for object status, as defined by the relative position of participants in the referential hierarchy.

\section{Conclusion}

The syntax of Araki shows sensitiveness to a number of contrasts in the real world, which it makes available for speakers and hearers to retrieve referents.

One first contrast is drawn between three-participant events. Those caused-motion verbs referring to transfer events that are semantically oriented towards the Theme (e.g. send, release...), treat it as the privileged argument, and encode it consistently as an object. Conversely, caused-possession verbs refer to events of transfer which are intrinsically successful (give, show, tell): because their Theme and Goal are potentially equally affectable, they are entitled to compete for the place of object.

Another functional contrast is drawn among referents with respect to their inherent ability to be affected by an event. In Araki, these referential splits play a role in two different parts of the system. Monotransitive verbs contrast their Patients based on their referential properties involving features such as humanness, specificity, topicality (Section 3). Likewise, the domain of ditransitive verbs is governed by a hierarchy in which humanness plays a central role, as well as the contrast of person between local and non-local referents (Section 4).

Evidently, the specifics of Araki verbal morphosyntax define a system that is typologically original. And yet, its general architecture remains deeply consistent with general tendencies observed elsewhere - including in the present volume - on the role played by referential properties in the grammatical encoding of arguments.

\section{References}

Andrews, Avery. 2007. The major functions of the noun phrase. Language Typology and Syntactic Description, vol. 1: Clause structure, ed. by Timothy Shopen, 132-224.

Cambridge: Cambridge University Press..

Bickel, Balthasar. 2010. Grammatical relations typology. The Oxford Handbook of Linguistic

Typology, ed. by Jae Jung Song, 399-444. Oxford: Oxford University Press.

Bickel, Balthasar andJohanna Nichols. 2009. Case marking and alignment. The Oxford

Handbook of Case, ed. by Andrej Malchukov and Andrew Spencer, 304-321. Oxford:

Oxford University Press.

Bossong, Georg. 1985. Empirische Universalienforschung. Differentielle Objektmarkierung in den Neuiranischen Sprachen. Tübingen: Narr. 
Branigan, Holly, P., Martin J. Pickering, Simon P. Liversedge, Andrew J. Stewart and Thomas P. Urbach. 1995. Syntactic priming: Investigating the mental representation of language. Journal of Psycholinguistic Research 24/6.489-506.

Dixon, R.M.W. and Alexandra Aikhenvald. 2000. Introduction. Changing Valency: Case Studies in Transitivity, ed. by R.M.W. Dixon and Alexandra Aikhenvald, 1-29 Cambridge: Cambridge University Press.

Dryer, Matthew S. 1986. Primary Objects, Secondary Objects, and Antidative. Language 62. 808-845.

Foley, William A. and Mike Olson. 1985. Clausehood and verb serialization. Grammar inside and outside the clause. Some approaches to theory from the field, ed. by Johanna Nichols and Anthony C. Woodbury, 17-60. Cambridge: Cambridge University Press.

François, Alexandre. 2002. Araki. A disappearing language of Vanuatu. Pacific Linguistics, 522. Canberra: Pacific Linguistics.

-----. 2003. La sémantique du prédicat en mwotlap (Vanuatu). Collection Linguistique de la Société de Linguistique de Paris, 84. Paris, Louvain: Peeters.

----. 2008. A new Araki-English-French dictionary. Paris: Lacito-CNRS.

Haspelmath, Martin. 2005. Argument marking in ditransitive alignment types. Linguistic Discovery 3/1.1-21.

-----. 2011. Ditransitive Constructions: The Verb 'Give'. The World Atlas of Language Structures Online, ed. by Matthew S. Dryer and Martin Haspelmath, chapter 105. Munich: Max Planck Digital Library,. [http://wals.info/chapter/105]

Heine, Bernd andTania Kuteva. 2002. World Lexicon of Grammaticalization. Cambridge: Cambridge University Press.

Hopper, Paul and Sandra Thompson. 1980. Transitivity in grammar and discourse. Language 56.253-299.

Jauncey, Dorothy G. 2010. Tamambo: the language of west Malo, Vanuatu. Pacific Linguistics 622. Canberra: Pacific Linguistics.

Kihm, Alain. 2000. Wolof Genitive Constructions and the Construct State. Research in Afroasiatic Grammar. Papers from the Third Conference on Afroasiatic Languages, Sophia Antipolis 1996) [Current Issues in Linguistic Theory 202], ed. by Jacqueline Lecarme, Jean Lowenstamm and Ur Shlonsky, 151-181. Amsterdam: John Benjamins.

Lazard, Gilbert. 1984. Actance variations and categories of the object. Objects. Towards a theory of grammatical relations, ed. by Franz Plank, 269-292. London, New York: Academic Press.

Lichtenberk, Frantisek. 1985. Possessive constructions in Oceanic languages and in ProtoOceanic. Austronesian Linguistics at the 15th Pacific Science Congress [Pacific Linguistics, C-88], ed. by Andrew Pawley and Lois Carrington, 93-140. Canberra: Pacific Linguistics.

Malchukov, Andrej, Martin Haspelmath and Bernard Comrie. 2010. Ditransitive constructions: A typological overview. Ditransitive constructions. A comparative handbook. ed. by Andrej Malchukov, Martin Haspelmath and Bernard Comrie, 1-64. Berlin: Mouton de Gruyter.

Margetts, Anna. 2007. Three-participant events in Oceanic languages. Oceanic Linguistics 46/1.71-127.

Miller, Amy. 2001. A grammar of Jamul Tiipay. Mouton Grammar Library 23. Berlin: Mouton de Gruyter.

Næss, Åshild. 2004. What markedness marks: the markedness problem with direct objects. Lingua 114/9-10.1186-1212.

-----. 2007. Prototypical transitivity. Amsterdam: Benjamins. 
Rappaport Hovav, Malka and Beth Levin. 2008. The English Dative Alternation: The Case for Verb Sensitivity. Journal of Linguistics 44.129-167.

Ross, Malcolm. 2004. The morphosyntactic typology of Oceanic languages. Language and Linguistics 5/2.491-541.

Siewierska, A. 2004. Person. Cambridge: Cambridge University Press.

Siewierska, Anna and Eva van Lier 2011. Introducing people and topics in Europe and beyond. Paper presented at the workshop for Semantic Role complexes. 4-5 April 2011, Zurich.

Silverstein, Michael. 1976. Hierarchy of Features and Ergativity. Grammatical Categories in Australian Languages, ed. by R.M.W. Dixon, 112-171. New Jersey: Humanities Press.

Van Gelderen, Elly. 2011. The linguistic cycle. Oxford: Oxford University Press.

Vari-Bogiri, Hannah. 2005. A Sociolinguistic Survey of Araki: A Dying Language of Vanuatu. Journal of Multilingual and Multicultural Development 26/1.52-66.

Author's Contact Information:

Dept of Linguistics

School of Culture, History and Language

Australian National University

ACT 0200, Australia

$\underline{\text { malexandre.francois@anu.edu.au }}$ 